\title{
Lumbar disc herniation: long-term outcomes after mini-open discectomy
}

\author{
Ahmed Benzakour $^{1}$ (D) Thami Benzakour $^{2}$
}

Received: 3 October 2019 / Accepted: 21 November 2019 / Published online: 9 December 2019

(C) SICOT aisbl 2019

We read with great interest the questions asked by Dr. Yueming Song [1], about our article "Lumbar disc herniation: long-term outcomes after mini-open discectomy" published in the special issue "Spine surgery and disc herniation" in International Orthopaedics [2].

Three questions were asked and our answers are as follows:

(1) Question about exclusion criteria: One of the exclusion criteria was scoliosis with Cobb angle $>15^{\circ}$. We considered that long-term outcomes of mini-open discectomy on patients with scoliosis were not as good as those without scoliosis. Including patients with scolioses could have been a selection bias. We think that mini-open discectomy is a good treatment for scoliotic patients with disc herniation; we just did not want to mix the outcomes of both scoliotic and non-scoliotic patients.

We also consider with respect your good results on 40 LDHs combined with scoliosis, but we also take note that the study includes wider angle deformity and may be a more painful symptomatology.

Therefore, our position is not to identify a contraindication, but only to stress the non- or moderately scoliotic patients.

In addition, no specific scoliosis classification was used because we wanted to analyse outcomes for non-scoliotic patients or with Cobb angle less than $15^{\circ}$.

(2) Concerning result deterioration during the follow-up. This trend had different distribution among the 552 patients but we did not study it precisely. We noticed that men, heavy workers, and patients who suffered a work accident had the poorest outcomes.

Ahmed Benzakour

benzak@hotmail.fr

1 Spine Surgery Department, Clinique de l'Archette, 83 rue Jacques Monod, 45160 Olivet, France

2 Zerktouni Orthopaedic Clinic, Casablanca, Morocco
Concerning the 40-50 age group, we also noticed the poorest results. This will be the purpose of our next study.

(3) Finally, in the discussion section, we stated that according to Cheng's study [3], mini-open discectomy has a longer interval time between initial surgery and revision comparatively to miniinvasive techniques. This author compared microendoscopic discectomy (MED), percutaneous endoscopic transforaminal discectomy (PETD), and open discectomy. One of the criteria in this study was the interval time between initial and revision surgery for these three techniques.

All mini-invasive techniques were not cited in this study but we chose to use it as a basis for our comparison because we considered that it was representing the most popular miniinvasive techniques used nowadays.

A similar interval time may not be sufficient to compare our study to Cheng's (our study 41.4 months and Cheng's study 33.1 months). Therefore, Dr. Song's remark, saying that we should not state that mini-open discectomy allows a longer time between initial surgery and revision, is understandable.

A more thorough study including all the minimally invasive techniques and open discectomy should be conducted to assert or invalidate this conclusion.

\section{References}

1. Xie T, Yang X, Song Y (2019) Letter to the editor concerning "Lumbar disc herniation: long-term outcomes after mini-open discectomy”. Int Orthop https://doi.org/10.1007/s00264-01904425-8

2. Benzakour A, Benzakour T (2019) Lumbar disc herniation: longterm outcomes after mini-open discectomy. Int Orthop 43:869-874. https://doi.org/10.1007/s00264-019-04312-2

3. Cheng J, Wang H, Zheng W et al (2013) Reoperation after lumbar disc surgery in two hundred and seven patients. Int Orthop 37:15111517. https://doi.org/10.1007/s00264-013-1925-2

Publisher's note Springer Nature remains neutral with regard to jurisdictional claims in published maps and institutional affiliations. 